\title{
Polyamines induce adaptive responses in water deficit stressed cucumber roots
}

\author{
Jan Kubiś • Jolanta Floryszak-Wieczorek • \\ Magdalena Arasimowicz-Jelonek
}

Received: 7 May 2013/Accepted: 29 May 2013/Published online: 10 August 2013

(C) The Author(s) 2013. This article is published with open access at Springerlink.com

\begin{abstract}
The aim of this study was to investigate the effect of exogenous polyamines (PAs) on the membrane status and proline level in roots of water stressed cucumber (Cucumis sativus cv. Dar) seedlings. It was found that water shortage resulted in an increase of membrane injury, lipoxygenase (LOX) activity, lipid peroxidation and proline concentration in cucumber roots during progressive dehydration. PA pretreatment resulted in a distinct reduction of the injury index, and this effect was reflected by a lower stress-evoked LOX activity increase and lipid peroxide levels at the end of the stress period. In contrast, PA-supplied stressed roots displayed a higher proline accumulation. The presented results suggest that exogenous PAs are able to alleviate water deficit-induced membrane permeability and diminish LOX activity. Observed changes were accompanied by an accumulation of proline, suggesting that the accumulation of this osmolyte might be another possible mode of action for PAs to attain higher membrane stability, and in this way mitigate water deficit effects in roots of cucumber seedlings.
\end{abstract}

Keywords Cucumber - Lipoxygenase $\cdot$ Membrane damage $\cdot$ Polyamines $\cdot$ Proline $\cdot$ Water deficit

\section{Abbreviations \\ LOX Lipoxygenase \\ PAs Polyamines}

J. Kubiś $(\bowtie) \cdot J$. Floryszak-Wieczorek

Department of Plant Physiology, Poznań University of Life

Sciences, Wołyńska 35, 60-637 Poznań, Poland

e-mail: jkubis@jay.up.poznan.pl

M. Arasimowicz-Jelonek

Department of Plant Ecophysiology, Adam Mickiewicz

University, Umultowska 89, 61-614 Poznań, Poland $\begin{array}{ll}\text { Put } & \text { Putrescine } \\ \text { Spd } & \text { Spermidine } \\ \text { Spm } & \text { Spermine }\end{array}$

\section{Introduction}

Drought stress is a major limitation to crop productivity. Thus to develop crop plants with an enhanced tolerance to drought stress, a basic understanding of physiological, biochemical and gene regulatory networks is essential (Valliodan and Nguyen 2006). Plants also respond and adapt to water deficit at both cellular and molecular levels, for instance by the accumulation of osmolytes and proteins specifically involved in stress tolerance (Shinozaki and Yamaguchi-Shinozaki 2007). Abiotic stresses, especially water deficit, increase biosynthesis of both polyamines (PAs) (Bouchereau et al. 1999; Kubiś 2003, 2008; Yang et al. 2007) and compatible osmolytes, such as sugars, betaines and proline (Hare and Cress 1997).

Since a lack of water induces PA accumulation (Flores 1991; Flores and Galston 1984a, b; Kakkar and Sawhney 2002; Turner and Stewart 1986, 1988), a growing interest is observed in the possible involvement of PAs in the adaptive mechanism of plants to various environmental stresses (Bouchereau et al. 1999). Biological functions of PAs are attributed to their polycationic character at a physiological $\mathrm{pH}$. Due to the presence of positively charged groups, PAs are able to bind strongly to negative charges in cellular components such as nucleic acids, proteins and phospholipids (Slocum et al. 1984; Smith 1985). An interaction of PAs with membrane phospholipids may stabilize membranes under stress conditions (Roberts et al. 1986), so its components may be buffered by 
PAs (Liu et al. 2007). PAs may directly or indirectly act as free radical scavengers (Bors et al. 1989). Spermine (Spm), which has four amino groups, is a more effective scavenger than spermidine (Spd), which has three amino groups, suggesting the involvement of amino groups in the inactivation of reactive oxygen species (ROS) (Besford et al. 1993). Indirectly, PAs are able to moderate the activities of scavenging system enzymes and alleviate oxidative stress intensity (Kubiś 2008). It has been shown that stress-tolerant plants increase endogenous PA levels to a greater extent than sensitive ones (Lee 1997). These molecules have been found to protect plants from abiotic stresses (Chattopadhayay et al. 2002; Liu et al. 2007; Shen et al. 2000); unfortunately, the precise mode of their action is not fully understood (Kakkar and Sawhney 2002). Additionally, through the enhancement of proline and betaine production PAs control and act as important osmoprotectant inducers in plat cells (Öztürk and Demir 2003).

A link between PAs and nitric oxide (NO) was shown by Tun et al. (2006) in Arabidopsis thaliana seedlings. These authors found that PAs induced NO biosynthesis, and another new mode of PA action via NO generation has already been confirmed that $\mathrm{NO}$ acts downstream of PAs in adaptive responses of cucumber leaves to water deficit stress (Yamasaki and Cohen 2006). Downregulation of NO by PAs was demonstrated in leaves of water-stressed cucumber plants by Arasimowicz-Jelonek et al. (2009). With regard to the finding reported by Gao et al. (2009), those higher levels of PAs and NO as well as the activities of arginine metabolism enzymes exist in roots rather than in leaves. It may be supposed that roots, especially new, fine ones, are much more exposed to many abiotic stresses, and are able to serve as an interface between plants and soil (Wells and Eissenstat 2003). According to the results of Gao et al. (2009), the authors also hypothesized that rootsourced molecules, i.e. PAs, are able to play a role in rootto-shoot signaling. This mode of action was proposed for PAs by Legocka and Kluk (2005). Results reported by those authors confirmed that osmotic and salt stresses induced PA biosynthesis in lupine roots, but Put accumulation in shoots, indicating root-to-shoot translocation, suggesting a potential role of PAs in root-to-shoot signaling.

Proline overproduction plays a highly protective role in plants that are exposed to abiotic stresses, conferring osmotic adjustment together with an increase in the levels of other osmolytes (Valliodan and Nguyen 2006). According to Yoshiba et al. (1997), compatible solutes could also be associated with lipids and proteins and thus counteracted negative dehydration effects on the cell structure and enzyme functioning. Other published data suggested other functions of proline, e.g. detoxification of ROS, and an interaction with the hydrophobic residue of proteins. The key role of proline in the response to water deficit has been demonstrated in transgenic tobacco that overexpressed proline biosynthesis enzymes (Kavi Kishor et al. 1995; Roosens et al. 2002). In turn, suppression of proline synthesis in transgenic plants resulted in increased sensitivity to water deficit (De Ronde et al. 2000). It was reported that transgenic petunia plants that overexpressed proline synthesis enzyme (pyrroline-5-carboxylate synthetase) genes from Arabidopsis (AtP5CS) and rice (OsP5CS) could withstand drought conditions longer than wild-type plants (Yamada et al. 2005).

In this study the role of PAs was analyzed in water deficit stress-induced changes in cucumber roots. Therefore it was attempted to determine whether exogenous PAsPut, Spd and Spm, might modify membrane stability, lipoxygenase (LOX) activity and osmolyte-proline accumulation in cucumber seedling roots.

\section{Materials and methods}

\section{Plant materials}

Roots of cucumber seedlings (Cucumis sativus cv. Dar) were used as plant materials for experiments. After germination of sterilized seeds for 2 days at $24{ }^{\circ} \mathrm{C}$ seedlings were placed ( 5 per $1.0 \mathrm{dm}^{3}$ beaker) and allowed to grow in a continuously aerated Hoagland's solution in a growth chamber with a photoperiod of $16 \mathrm{~h}$ [light$250 \mu \mathrm{mol} \mathrm{m} \mathrm{m}^{-2} \mathrm{~s}^{-1}$ photosynthetically active radiation (PAR) ] at the temperature of $24{ }^{\circ} \mathrm{C}$ (day) and $20^{\circ} \mathrm{C}$ (night), and $60-70 \%$ humidity. The nutrient solution was renewed once a week.

\section{PA treatment}

One-month-old seedlings were taken out and divided into four groups. Their roots were immersed in the following, continuously aerated solutions: $1 \mathrm{mM} \mathrm{K}$-phosphate buffer, pH 5.8 (control), or in buffer solutions containing additionally $1 \mathrm{mM}$ Put, or Spd, or Spm, and maintained for $24 \mathrm{~h}$ under controlled conditions $\left(22{ }^{\circ} \mathrm{C}\right.$, humidity $65 \%$, continuous light of $\left.150 \mu \mathrm{mol} \mathrm{m}{ }^{-2} \mathrm{~s}^{-1} \mathrm{PAR}\right)$.

\section{Stress conditions}

Half of the plants from each group was transferred into empty beakers and subjected to dehydration for $10 \mathrm{~h}$ (stressed plants). The other half of each plant group was maintained with their roots in $1 \mathrm{mM} \mathrm{K}$-phosphate continuously aerated buffer, pH 5.8 (control plants). Then beakers with seedlings were placed in a growth chamber under controlled conditions $\left(22{ }^{\circ} \mathrm{C}\right.$, humidity of $65 \%$ at 
continuous light of $150 \mu \mathrm{mol} \mathrm{m} \mathrm{m}^{-2} \mathrm{~s}^{-1}$ PAR). Finally the roots were collected at 0,5 , and $10 \mathrm{~h}$ after withdrawal of water, and $24 \mathrm{~h}$ after rewatering (roots immersed in buffer) of $10 \mathrm{~h}$-long stressed plants. Each sample contained 10 seedlings.

\section{Relative water content (RWC)}

Indicating the level of water stress in roots, RWC was estimated according to Weatherley (1950), and calculated according to the following formula: $\mathrm{RWC}=[$ (fresh weight - dry weight)/(fresh weight at full turgor-dry weight)] $100 \%$.

\section{Injury index}

Electrolyte leakage from the roots was determined by the conductivity method and used as a criterion of injury. The amounts of electrolytes released from stressed or control tissues were compared to total electrolyte amounts released after boiling. The injury index was calculated according to a formula given by Flint et al. (1967): $I_{D}=\left(L_{D}-L_{0}\right) /$ $\left(100-\mathrm{L}_{0}\right) \cdot 100 \%$, where $\mathrm{I}_{\mathrm{D}}$ is the injury index, $\mathrm{L}_{0}$ is an electrolyte leakage from the control tissue in percent of the total electrolyte content, and $\mathrm{L}_{\mathrm{D}}$ is an electrolyte leakage from the desiccated tissue in percent of the total electrolyte content. Determinations were performed in five replicates, each using the whole root system of an individual plant.

\section{LOX activity}

Enzyme activity was measured according to Borrell et al. (1997). The increase in absorbance was monitored at $234 \mathrm{~nm}$ wavelengths. An absorbance increase of 0.001 was taken as one unit of LOX activity. Protein content in the extracts was determined according to Bradford (1976). Determinations were performed in five replicates and LOX activity was expressed in units per mg protein content.

\section{Proline determination}

This metabolite content was performed according to the method given by Bates et al. (1973). The quantity of the colored reaction product of proline with ninhydric acid was measured. Absorbance was recorded at $520 \mathrm{~nm}$ and the amount of proline was calculated from the standard curve and expressed in $\mu \mathrm{g} \times \mathrm{g}^{-1}$ dry matter. Determination was performed in 5 replications.

Histochemical detection of lipid peroxidation

For lipid peroxidation freshly harvested roots were stained in Schiff's reagent for 60 min until pink color appeared, and then extra stain was removed by rinsing in potassium sulphite solution $\left[0.5 \%(\mathrm{w} / \mathrm{v}) \mathrm{K}_{2} \mathrm{~S}_{2} \mathrm{O}_{5}\right.$ in $\left.0.05 \mathrm{M} \mathrm{HCl}\right]$ as in Pompella et al. (1987). The lipid peroxidation range was estimated as thiobarbituric acid reactive substances in nmol per $1 \mathrm{~g}$ dry weight (DW).

Statistical analysis

Analyses were performed in three to six replications and the data are presented as a mean \pm standard deviation (SD). Experimental data were subjected to a one-way analysis of variance (ANOVA) and significant differences between means were determined by Tukey's multiple range test. Data (stressed plants) significantly different from respective control (-PAs) at $P<0.05$ were marked with a single asterisk on the figures.

\section{Results}

Water deficit greatly lowered RWC of cucumber roots, by as much as $60-65 \%$ (Fig. 1) at the end of the 10-h stress period. In stressed plants treated with PAs, the dynamics of water content decrease was similar to that observed for untreated plants. There were no differences in RWC between PA-treated and untreated control plants. After rewatering the water content returned fast to the level recorded in unstressed plants (79-86\%).

Water stress induced a marked increase in membrane permeability (Fig. 2), from approximately $12 \%$ at $5 \mathrm{~h}$ to $17 \%$ at $10 \mathrm{~h}$. Generally, plants treated with PAs showed a significant reduction of stress-induced electrolyte leakage,

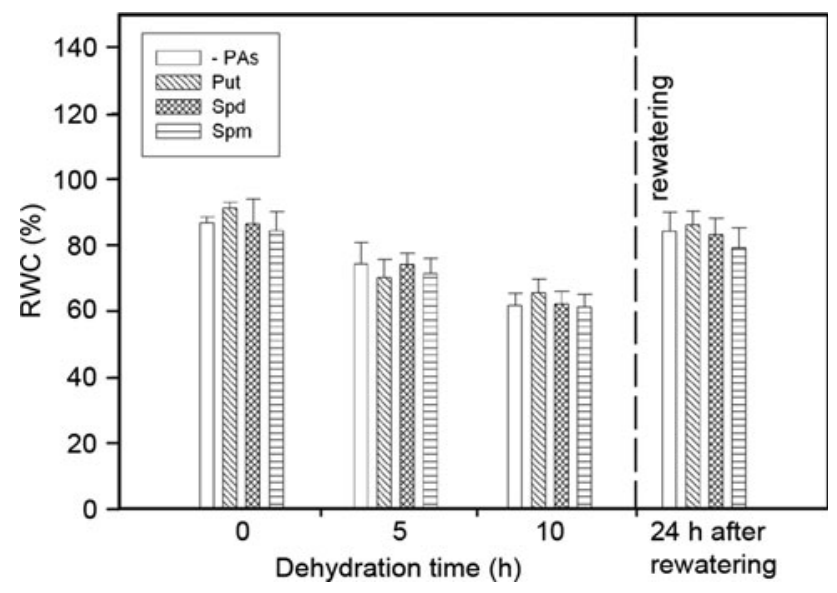

Fig. 1 The effect of exogenous PAs on the relative water content during progressive dehydration of cucumber roots. Measurements were made 0,5 and $10 \mathrm{~h}$ after water withholding and $24 \mathrm{~h}$ after rewatering. Prior to stress plants were immersed in: buffer (-PAs), $1.0 \mathrm{mM}$ Put, $1.0 \mathrm{mM}$ Spd and $1.0 \mathrm{mM} \mathrm{Spm}$. Values indicate mean \pm SE with $n=5$ 


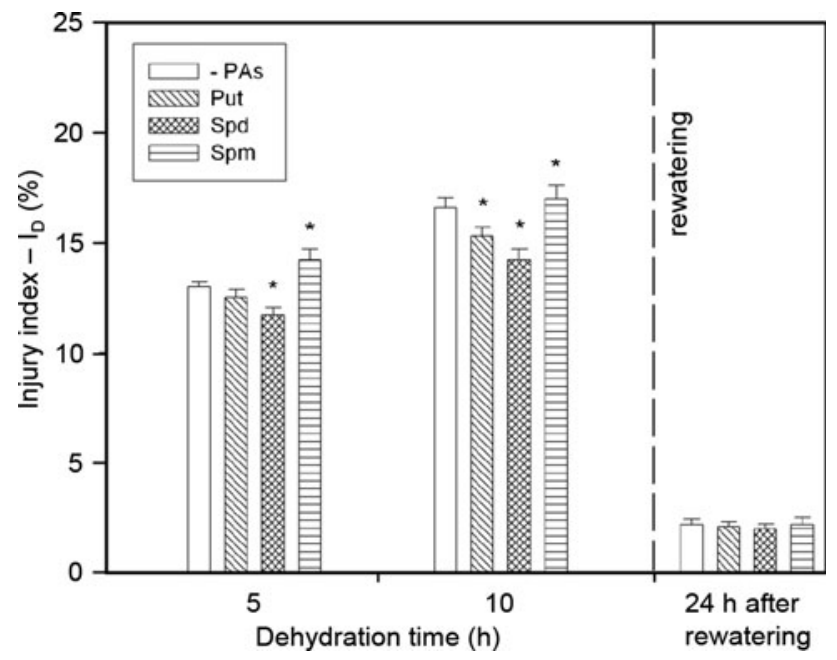

Fig. 2 The effect of exogenous PAs on the injury index $\left(\mathrm{I}_{\mathrm{D}}\right)$ during progressive dehydration of cucumber roots. Measurements were made 5 and $10 \mathrm{~h}$ after water withholding and $24 \mathrm{~h}$ after rewatering. Prior to stress plants were immersed in: buffer (-PAs), $1.0 \mathrm{mM}$ Put, $1.0 \mathrm{mM}$ Spd and $1.0 \mathrm{mM} \mathrm{Spm}$. Values indicate mean $\pm \mathrm{SE}$ with $n=5$. Data (stressed plants) significantly different from respective control: $* P<0.05$

depending on water stress duration. Pretreatment with Put and Spd resulted in a reduction of leakage consecutively by ca. 6 and $9 \%$ at $5 \mathrm{~h}$, respectively, and 7 and $20 \%$ at $10 \mathrm{~h}$, respectively, of dehydration in comparison with the untreated plants. In contrast, when seedlings were treated with Spm, a very slight increase in membrane damage was observed as compared to untreated seedlings. After rewatering, the injury index slowly decreased to the level comparable with that in the unstressed plants. In wellwatered plants, either treated or untreated with PAs, practically no differences were observed in membrane permeability after $24 \mathrm{~h}$ of the experiment.

Water stress induced a significant increase in LOX activity (Fig. 3), which was noted as early as $5 \mathrm{~h}$ after dehydration (50\%). After $10 \mathrm{~h}$ of stress duration, an $80 \%$ increase of LOX activity was recorded as compared to LOX of unstressed roots. PA application before water loss caused time-dependent changes in LOX activity: when compared with untreated roots, LOX activity in seedlings pretreated with Spd, Put and Spm increased by 20, 10 and $10 \%$, respectively, after $5 \mathrm{~h}$ of dehydration, then decreased by 10,15 and $7 \%$, respectively, after $10 \mathrm{~h}$ of dehydration. After rewatering, LOX activity gradually dropped to the level observed in the unstressed plants. In seedlings pretreated with PAs, LOX activity remained slightly lower than in untreated ones.

Plant dehydration induced a gradual proline accumulation in cucumber seedlings (Fig. 4); over fivefold in leaves, four-fold in roots but only threefold in shoots, compare with plants not subjected to stress (time 0 ). When seedlings

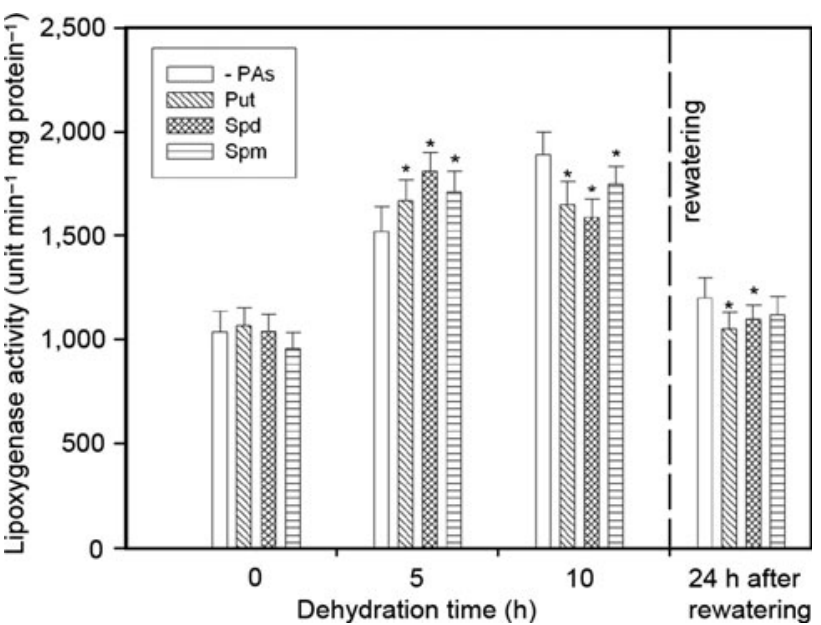

Fig. 3 The effect of exogenous PAs on the LOX specific activity during progressive dehydration of cucumber roots. Measurements were made 0,5 and $10 \mathrm{~h}$ after water withholding and $24 \mathrm{~h}$ after rewatering. Prior to stress plants were immersed in: buffer (-PAs), $1.0 \mathrm{mM}$ Put, $1.0 \mathrm{mM}$ Spd and $1.0 \mathrm{mM} \mathrm{Spm}$. Values indicate mean $\pm \mathrm{SE}$ with $n=6$. Asterisk see Fig. 2

were treated with exogenously supplied PAs, a definitely higher accumulation of proline was observed after stress treatment: stressed roots pretreated with Put, Spd and Spm exhibited 24, 57 and $29 \%$ higher accumulation, respectively, after $5 \mathrm{~h}$; and 45, 100 and $72 \%$ higher accumulation, respectively, after $10 \mathrm{~h}$ of stress duration, compared to PA-untreated stressed roots. Similarly, stressed shoots pretreated with Put, Spd and Spm exhibited 41, 78 and $59 \%$ higher accumulation of proline after $5 \mathrm{~h}$; and 16, 45 and $19 \%$ higher accumulation after $10 \mathrm{~h}$ of stress duration, compared to PA-untreated shoots. Leaves pretreated with Put, Spd and Spm exhibited 15, 80 and $12 \%$ increases, respectively, after $5 \mathrm{~h}$; and 26, 96 and $57 \%$ increases after $10 \mathrm{~h}$ of stress duration, compared to PA-untreated leaves. With regard to seedlings not subjected to water deficit stress and treated with PAs, all estimated parameters generally remained on a stable level during the experiment and these data were not presented in the figures.

For visualization of the membrane damage of root tissues, histochemical detection of lipid peroxidation was performed at 5 and $10 \mathrm{~h}$ of dehydration (Fig. 5). The intensive pink staining of Schiff's reagent, a specific reaction for lipid peroxidation, was observed in PAuntreated root seedlings after $10 \mathrm{~h}$ of dehydration. In contrast, cucumber roots treated with PAs, especially with Spd, showed weaker dye (pink) staining compared to nontreated plants at $10 \mathrm{~h}$ of dehydration. At $5 \mathrm{~h}$ of dehydration, the pink coloring was mainly confined to the subapical zone of roots from untreated seedlings. In plants not subjected to dehydration or after rewatering, no pink staining was observed (data not shown). On the base of 

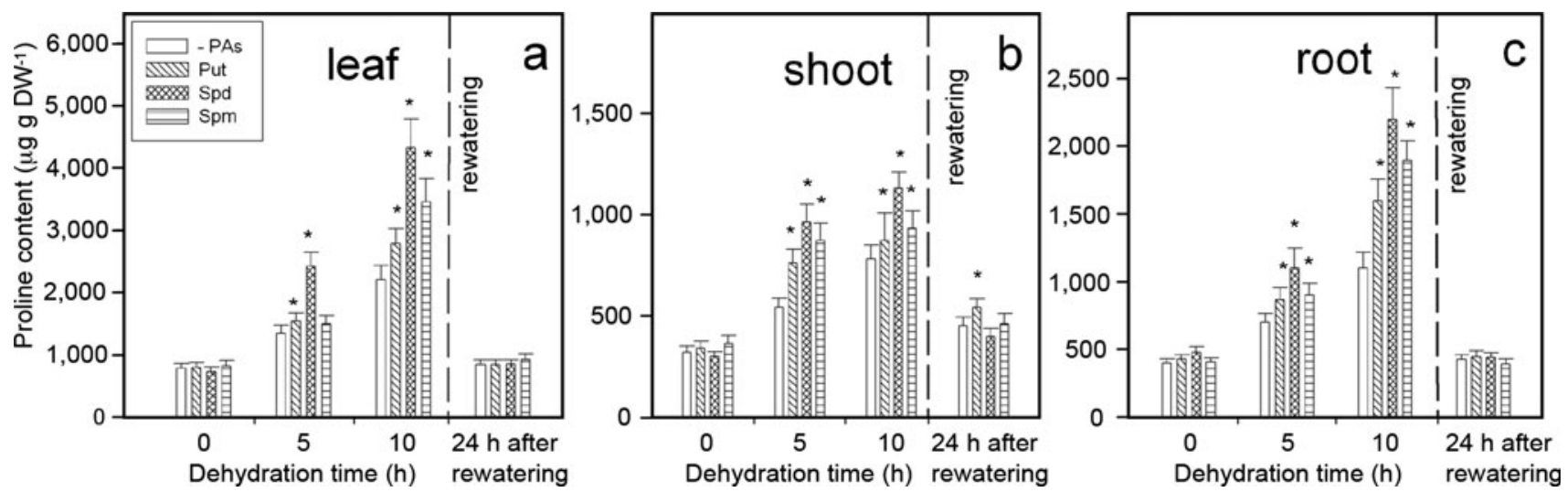

Fig. 4 The effect of exogenous PAs on the proline content in leaf (a), shoot (b) and root (c) during progressive dehydration of cucumber and $24 \mathrm{~h}$ after rewatering. Prior to stress plants were immersed in: buffer (-PAs), $1.0 \mathrm{mM}$ Put, $1.0 \mathrm{mM}$ Spd and $1.0 \mathrm{mM}$ Spm. Values seedlings. Measurements were made 0 to $10 \mathrm{~h}$ after water withholding

Fig. 5 Histochemical detection of lipid peroxidation were performed by staining of Schiff's reagent at $5(\mathbf{a}-\mathbf{d})$ and $10 \mathrm{~h}(\mathbf{e}-\mathbf{h})$ of dehydration. The intensive grey (originally pink in a PDF version) color indicate a specific reaction for lipid peroxidation. Prior to stress plants roots were immersed in: buffer (-PAs a and e), $1.0 \mathrm{mM}$ Put (b and f), $1.0 \mathrm{mM} \mathrm{Spd}$ (c and $\mathbf{g}$ ) and $1.0 \mathrm{mM} \mathrm{Spm}$ (d and $\mathbf{h}$ )

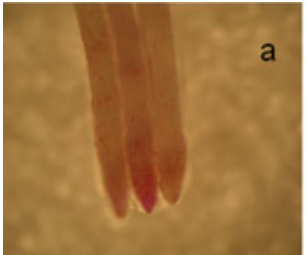

$5 \mathrm{~h}$ - PAs

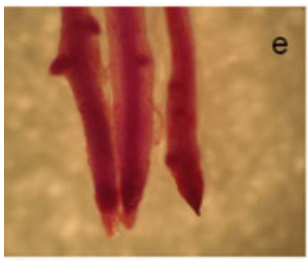

$10 \mathrm{~h}$ - PAs

\begin{tabular}{|l|c|l|c|}
\hline color & lipid peroxidation ${ }^{*}$ & color & lipid peroxidation * \\
\hline & not detectable & & $0.75-1.0$ \\
\hline & $0.5-0.75$ & & $1.0-1.25$ \\
\hline
\end{tabular}

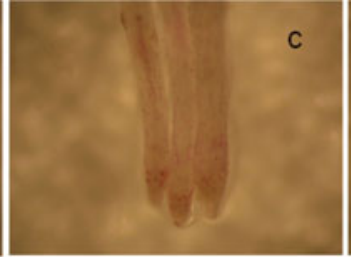

$5 \mathrm{~h} \mathrm{Spd}$

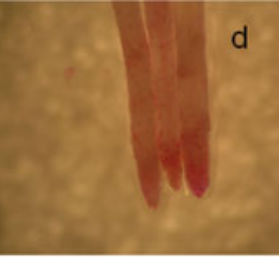

$5 \mathrm{~h} \mathrm{Spm}$
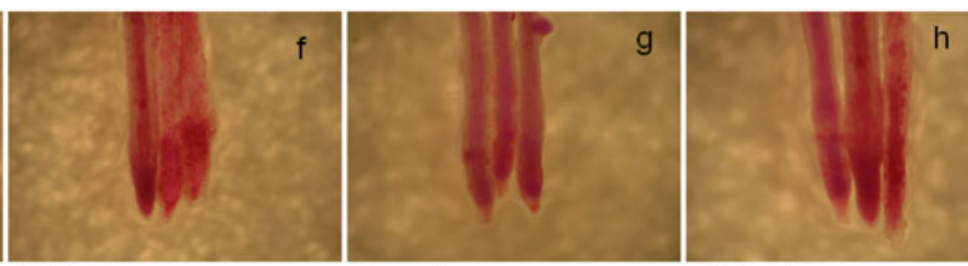

10 h Spm visualization no lipid peroxidation was detected and additionally the results of very small membrane damage (Fig. 2) were confirmed.

\section{Discussion}

Plants respond in order to survive under water-deficit conditions via a series of physiological, cellular, and molecular processes culminating in stress tolerance. These adaptive changes include ABA synthesis and ABA-mediating phenomena, i.e. stomatal closure, PA and proline accumulation and changes within cell membranes (Lafitte et al. 2007; Shinozaki and Yamaguchi-Shinozaki 2007).
Obtained results provide evidence that cucumber seedlings treated with Spd exhibited a higher membrane stability under stress conditions, as reflected in a significant reduction of the stress-induced electrolyte leakage (Fig. 2) confirmed by visualization of the membrane damage (Fig. 5). Similar effects of higher levels of PA, Spd and Spm on the leakage of electrolytes and amino acids from salt-stressed rice roots have been reported by Chattopadhayay et al. (2002). They concluded that exogenous Spd and Spm are effective in triggering protection against cellular and macromolecular damage of rice plants during salinity stress, probably by maintaining membrane integrity and/or inhibiting protease and RNase activity during stress. On the other hand, it has been reported that PAs might 
mediate a decrease in ion fluxes across the vacuolar membrane by blocking fast-activating vacuolar channels under salt stress, as suggested by Bruggemann et al. (1998).

Progressive water shortage resulted in a water deficitevoked increase in LOX activity (Fig. 3). Stress-induced LOX activation was also reported in desiccated soybean leaves (Kacperska and Kubacka-Zębalska 1989), in senescing muskmelon tissues (Lester 2000), and in barley and cucumber leaves subjected to water deficit (Arasimowicz-Jelonek et al. 2009; Kubiś 2006). In contrast, in chives tolerant to drought, a lower level of LOX activity under stress was noted (Egert and Tevini 2002).

Cucumber plants pretreated with PAs exhibited timedependent changes in the stress-evoked activity of LOX as compared to PA-untreated stressed seedlings (Fig. 3). Barley plants pretreated with Spd prior to water shortage showed a higher, water deficit stress-evoked activity of LOX than PA-untreated stressed plants (Kubiś 2006). From our experiment we concluded that Spd protected soluble proteins against the water stress-induced decrease. Therefore, it may be speculated that an early increase in LOX activity $(5 \mathrm{~h})$ in the PA-pretreated water stressed tissues could be possibly due to LOX-protein protection. It has been shown that in maize Spd may bind to the $18-\mathrm{kD}$ membrane protein (Tassoni et al. 2002) and in this way modulate activities of many enzymes such as protein kinases, phosphatases and ATPases (Tassoni et al. 1998). From the results cited above we may speculate that PA protection of LOX-proteins can also be possible. Moreover, lipid hydroperoxides produced by LOX served as substrates for stress-induced jasmonic acid (JA) biosynthesis (Rosahal 1996; Creelman and Mullet 1997) without modifying membrane stability.

Performed histochemical detection of lipid peroxidation resulted in intensive staining of Schiff's reagent (originally pink) after $10 \mathrm{~h}$ of dehydration (Fig. 5, $10 \mathrm{~h}$-PAs) and weaker staining after $5 \mathrm{~h}$ of dehydration (Fig. $5,5 \mathrm{~h}$-PAs) in whole regions of PA-untreated seedlings. In contrast, treatments of Spd and Put diminished staining, which was relatively confined to the tip regions of treated roots after $5 \mathrm{~h}$ (Fig. 5, $5 \mathrm{~h}$ Put and $5 \mathrm{~h} \mathrm{Spd)}$ and less intensely in the whole root of treated roots after $10 \mathrm{~h}$ (Fig. 5, $10 \mathrm{~h}$ Put and $10 \mathrm{~h} \mathrm{Spd}$ ) of dehydration, suggesting membrane damages. In water-stressed barley leaves, Kubiś (2006) indicated that a significant twofold increase in LOX activity did not correspond with the relatively lower malonyldialdehyde (MDA) increase (48\%) after $24 \mathrm{~h}$ of dehydration. In addition, Spd pretreatment caused a three-fold increase in LOX activity, but only an approximately $30 \%$ increase in MDA concentrations. It was suggested that the consumption of hydroperoxides produced by LOX can be a reason for lower membrane dysfunction, and PAs are engaged in alleviation of this effect in water-stressed barley seedlings.
The involvement of methyl jasmonate in polyamine metabolism and in cell protection against another type of stress, i.e. pathogen infection, was earlier indicated (Biondi et al. 2001; Walters et al. 2002).

Our observations provide evidence that water deficit altered time-dependent proline accumulation in cucumber seedlings. The most significant, five-fold increase was observed in leaves, fourfold in roots and threefold in shoots. Bandurska and Stroiński (2003) also reported that in barley an earlier and significant increase was observed in leaves whereas in roots the accumulation was less significant. Observed in this work an effect of proline accumulation due to water deficit is in line with the results obtained by Handa et al. (1986), Raggi (1994), Bandurska (2000, 2001), and Knipp and Honermeir (2006), Najaphy et al. (2010). This amino acid is supposed to play a significant role in osmotic adjustment with regard to a reduction of osmotic potential due to the accumulation of solutes, and enables cells to maintain turgor during water deficit stresses (Ashraf and Foolad 2007; Lopez-Carrion et al. 2008). Our data indicated that cucumber seedlings, treated with PAs, especially with Spd, prior to water deficit, exhibited a definitely higher stress-evoked proline accumulation. In turn, the induction of proline accumulation might be an important mechanism for plants to tolerate severe stress conditions (Ruan et al. 2004).

It is well documented that PAs are able to induce adaptive changes in water stressed plants; it is of the prime importance to maintain plasma membrane integrity under water deficit conditions. Pretreatment of cucumber roots with PAs resulted in a distinct reduction of the injury index and this observed PA effect was mirrored by a lower stressevoked LOX activity increase in stressed seedlings at a severe water deficit. The other possible mechanism of the PA mode of action is an osmotic adjustment due to the accumulation of solutes, enabling cells to maintain turgor during water shortage. In seedlings supplied with PAs prior to stress, a significantly higher osmolyte-proline accumulation was recorded.

It allows us to speculate that under water deficit stress accumulated PAs could act as signal molecules and may trigger efficient adaptive mechanisms, resulting in the alleviation of negative drought effects. Additionally, these root-sourced signaling molecules are able to play an important role in root-to-shoot signaling and help to adapt plants to drought and prevent crops from serious stresscaused damages.

Open Access This article is distributed under the terms of the Creative Commons Attribution License which permits any use, distribution, and reproduction in any medium, provided the original author(s) and the source are credited. 


\section{References}

Arasimowicz-Jelonek M, Floryszak-Wieczorek J, Kubiś J (2009) Signal interaction between polyamines and nitric oxide intermediates cucumber adaptive responses to drought. J Plant Growth Regul 28:177-186

Ashraf M, Foolad MR (2007) Roles of glycine betaine and proline in improving plant abiotic stress resistance. Env Exp Bot 59:206-216

Bandurska H (2000) Does proline accumulated in leaves of water deficit stressed barley plants confine cell membrane injury? I. Free proline accumulation and membrane injury index in drought and osmotically stressed plants. Acta Physiol Plant 22:409-415

Bandurska H (2001) Does proline accumulated in leaves of water deficit stressed barley plants confine cell membrane injury? II. Proline accumulation during hardening and its involvement in reducing membrane injury in leaves subjected to severe osmotic stress. Acta Physiol Plant 23:483-490

Bandurska H, Stroiński A (2003) ABA and proline accumulation in leaves and roots of wild (Hordeum spontaneum) and cultivated (Hordeum vulgare 'Maresi') barley genotypes under water deficit conditions. Acta Physiol Plant 25:55-61

Bates LS, Waldren RP, Teare JD (1973) Rapid determination of proline for water stress studies. Plant Soil 39:205-207

Besford RT, Richardson JL, Campos AF, Tiburcio AF (1993) Effect of polyamines in stabilization of molecular complexes of thylakoid membranes of osmotically stressed oat leaves. Planta 189:201-206

Biondi S, Scaramagli S, Capitani F, Altamura MM, Torrigiani P (2001) Methyl jasmonate upregulates biosynthetic gene expression, oxidation and conjugation of polyamines, and inhibits shoot formation in tobacco thin layers. J Exp Bot 52:231-242

Borrell A, Carbonell R, Farras R, Puig-Parellada P, Tiburcio AF (1997) Polyamines inhibit lipid peroxidation in senescing oat leaves. Physiol Plant 99:385-390

Bors N, Langebartels C, Michel C, Sanderman H (1989) Polyamines as radical scavengers and protectants against ozone damage. Phytochem 28:1589-1595

Bouchereau A, Aziz A, Larher F, Martin-Tanguy J (1999) Polyamines and environmental challenges: recent development. Plant Sci 140:103-125

Bradford MM (1976) A rapid and sensitive method for the quantitation of microgram quantities of protein utilizing the principle of protein-dye binding. Anal Biochem 72:248-254

Brüggemann LI, Pottosin II, Schőnknecht G (1998) Cytoplasmic polyamines block the fast-activating vacuolar cation channels. Plant J 16:101-105

Chattopadhayay MK, Tiwari BS, Chattopadhayay G, Bose A, Sengupta DN, Ghosh B (2002) Protective role of exogenous polyamines on salinity-stressed rice (Oriza sativa) plants. Physiol Plant 116:192-199

Creelman RA, Mullet JE (1997) Biosynthesis and action of jasmonates in plants. Annu Rev Plant Physiol Plant Mol Biol 48:355-381

De Ronde JA, Spreeth MH, Cress WA (2000) Effect of antisense ${ }_{L}-\Delta 1$ -pyrroline-5-carboxylate reductase transgenic soybeen plants subjected to osmotic and drought stress. Plant Growth Regul 32:13-26

Egert M, Tevini M (2002) Influence of drought on some physiological parameters symptomatic for oxidative stress in leaves of chives (Alium schoenoprasum). Env Exp Bot 48:43-49

Flint HZ, Boyce BR, Brattie DJ (1967) Index of injury-a useful expression of freezing injury of plants tissues as determined by electric conductivity method. Can J Plant Sci 47:229-239
Flores HE (1991) Changes in polyamine metabolism in response to abiotic stress. In: Slocum RD, Flores HE (eds) The biochemistry and physiology of polyamines in plants. CRC Press, Boca Raton, pp 214-255

Flores HE, Galston AW (1984a) Osmotic stress-induced polyamine accumulation in cereal leaves. I. Physiological parameters of the response. Plant Physiol 75:102-109

Flores HE, Galston AW (1984b) Osmotic stress-induced polyamine accumulation in cereal leaves. II. Relation to amino acid pools. Plant Physiol 75:110-113

Gao HJ, Yang HQ, Wang JX (2009) Arginine metabolism in roots and leaves of apple (Malus domestica Borkh.): the tissue specific formation of both nitric oxide and polyamines. Sci Horti 119:147-152

Handa S, Handa AK, Hasegawa PM, Bressan RA (1986) Proline accumulation and adaptation of cultured plant cells to water stress. Plant Physiol 80:938-945

Hare PD, Cress WA (1997) Metabolic implications of stress-induced proline accumulation in plants. Plant Growth Regul 21:79-102

Kacperska A, Kubacka-Zębalska M (1989) Formation of stress ethylene depends both on ACC synthesis and on the activity of free radical-generating system. Physiol Plant 77:231-237

Kakkar RK, Sawhney VK (2002) Polyamine research in plants-a changing perspective. Physiol Plant 116:281-292

Kavi Kishor PB, Hong Z, Miao GH, Hu CAA, Verma DPS (1995) Overexpression of $\Delta^{1}$-pyrroline-5-carboxylate synthetase increases proline production and confers osmotolerance in transgenic plants. Plant Physiol 108:1387-1394

Knipp G, Honermeir B (2006) Effect of water stress on proline accumulation of genetically modified potatoes (Solanum tuberosum L.) generating fructans. J Plant Physiol 163:392-397

Kubiś J (2003) Polyamines and "scavenging system": influence of exogenous spermidine on catalase and guaiacol peroxidase activities, and free polyamines level in barley leaves under water deficit. Acta Physiol Plant 25:337-343

Kubiś J (2006) Exogenous spermidine alters in different way membrane permeability and lipid peroxidation in water stressed barley leaves. Acta Physiol Plant 28:27-33

Kubiś J (2008) Exogenous spermidine alters in different ways activities of some scavenging system enzymes, $\mathrm{H}_{2} \mathrm{O}_{2}$ and superoxide radical levels in water stressed cucumber leaves. J Plant Physiol 165:397-406

Lafitte HR, Yongsheng G, Yan S, Li Z-K (2007) Whole plant responses, key processes, and adaptation to drought stress: the case of rice. J Exp Bot 58:169-175

Lee TM (1997) Polyamine regulation of growth and chilling tolerance of rice (Oryza sativa L.) roots cultured in vitro. Plant Sci 122:111-117

Legocka J, Kluk A (2005) Effect of salt and osmotic stress on changes in polyamine content and arginine decarboxylase activity in Lupinus luteus seedlings. J Plant Physiol 162:662-668

Lester GE (2000) Polyamines and their cellular anti-senescence properties in honey dew muskmelon fruit. Plant Sci 160:105-112

Liu JH, Kitashiba H, Wang J, Ban Y, Moriguchi T (2007) Polyamines and their ability to provide environmental stress tolerance. Plant Biotechnol 24:117-126

Lopez-Carrion AI, Castellano R, Rosales MA, Ruiz JM, Romero L (2008) Role of nitric oxide under saline stress: implications on proline metabolism. Biol Plant 52:587-591

Najaphy A, Niari khamssi N, Mostafaie A, Mirzaee H (2010) Effect of progressive water deficit stress on proline accumulation and protein profiles of leaves in chickpea. Afric J Biotech 9:7033-7036

Öztürk L, Demir Y (2003) Effects of putrescine and ethephon on some oxidative stress enzyme activities and proline content in salt stressed spinach leaves. Plant Growth Regul 40:89-95 
Pompella A, Maellaro E, Casini AF, Comporti M (1987) Histochemical detection of lipid peroxidation in the liver of bromobenzenepoisoned mice. Am J Pathol 129:295-301

Raggi V (1994) Changes in free amino acid and osmotic adjustment in leaves of water-stressed been. Physiol Plant 91:427-434

Roberts DR, Dumdroff EB, Thompson JE (1986) Exogenous polyamines alter membrane fluidity in been leaves: a basic potential misinterpretation of their physiological role. Planta 167:395-401

Roosens NH, Bitar F, Loenders K, Angenon G, Jacobs M (2002) Overexpression of ornithine- $\delta$-aminotransferase increases pro biosynthesis and osmotolerance in transgenic plants. Mol Breed 9:73-80

Rosahal S (1996) Lipoxygenases in plants-their role in development and stress responses. Z Naturforsch 51c:123-138

Ruan HH, Shen WB, Xu LL (2004) Nitric oxide involved in the abscisic acid induced proline accumulation in wheat seedling leaves under salt stress. Acta Biol Sin 46:1307-1315

Shen W, Nada K, Tachibana S (2000) Involvement of polyamines in the chilling tolerance of cucumber cultivars. Plant Physiol 124:431-439

Shinozaki K, Yamaguchi-Shinozaki K (2007) Gene networks involved in drought stress response and tolerance. J Exp Bot 58:221-227

Slocum RD, Kaur-Sawhney R, Galston AW (1984) The physiology and biochemistry of polyamines in higher plants. Arch Biochem Biophys 235:283-303

Smith TA (1985) Polyamines. Ann Rev Plant Physiol 36:117-143

Tassoni A, Antognoni F, Battistini ML, Sanvido O, Bagni N (1998) Characterization of spermidine binding to solubilized plasma membrane proteins from zucchini hypocotyls. Plant Physiol 117:971-977

Tassoni A, Napier RM, Franceschetti M, Venis MA, Bagni N (2002) Spermidine-binding proteins. Purification and expression analysis in maize. Plant Physiol 128:1303-1312

Tun NN, Santa-Catarina C, Begum T, Silveira V, Handro W, Floh IS, Scherer FE (2006) Polyamines induce rapid biosynthesis of nitric oxide (NO) in Arabidopsis thaliana seedlings. Plant Cell Physiol 47:346-354

Turner LB, Stewart GR (1986) The effect of water stress upon polyamine levels in barley (Hordeum vulgare L.) leaves. J Exp Bot 175:170-177

Turner LB, Stewart GR (1988) Factors affecting polyamine accumulation in barley (Hordeum vulgare L.) leaf sections during osmotic stress. J Exp Bot 200:311-316

Valliodan B, Nguyen HT (2006) Understanding regulatory networks and engineering for enhanced drought tolerance in plants. Cur Opin Plant Biol 9:1-7

Walters D, Cowley T, Mitchell A (2002) Methyl jasmonate alters polyamine metabolism and induces systemic protection against powdery mildew infection in barley seedlings. J Exp Bot 53:747-756

Weatherley PE (1950) Studies in water relations of cotton plants. I. The field measurement of water deficits in leaves. New Phytol 49:81-97

Wells CE, Eissenstat DM (2003) Beyond the roots of young seedlings: the influence of age and order on fine root physiology. J Plant Growth Regul 21:324-334

Yamada M, Morishita H, Urano K, Shiozaki N, Yamaguhi-Shinozaki K, Shinozaki K, Yoshiba Y (2005) Effects of free proline accumulation in petunias under drought stress. J Exp Bot 56:1975-1981

Yamasaki H, Cohen MF (2006) NO signal at crossroads: polyamine induced nitric oxide synthesis in plants. Trends Plant Sci $11: 522-524$

Yang J, Zhang J, Liu K, Wang Z, Liu Z (2007) Involvement of polyamines in the drought resistance of rice. J Exp Bot 58:1545-1555

Yoshiba Y, Kiyosue T, Nakashima K, Yamaguchi-Shinozaki K, Shinozaki K (1997) Regulation of levels of proline as an osmolytes in plants under water stress. Plant Cell Physiol 18:1095-1102 